\title{
Correction to: Path calculation of 7-axes synchronous quasi-tangential laser manufacturing
}

\author{
Norbert Ackerl $^{1} \cdot$ Maximilian Warhanek $^{1} \cdot$ Johannes Gysel $^{1} \cdot$ Konrad Wegener $^{1}$
}

Published online: 9 May 2019

(C) Springer-Verlag London Ltd., part of Springer Nature 2019

\section{Correction to: The International Journal of Advanced Manufacturing Technology} https://doi.org/10.1007/s00170-019-03540-5

The original version of this article contained a mistake.

The formulae and signs are not shown correctly in Fig. 5.

The correct images are shown below.

Fig. 5 Rolled off and stitched geometry with vectors separating the top and bottom groove (a). The projection in the $x y^{\prime}$-plane allows the calculation with a polynomial for each segment (b)
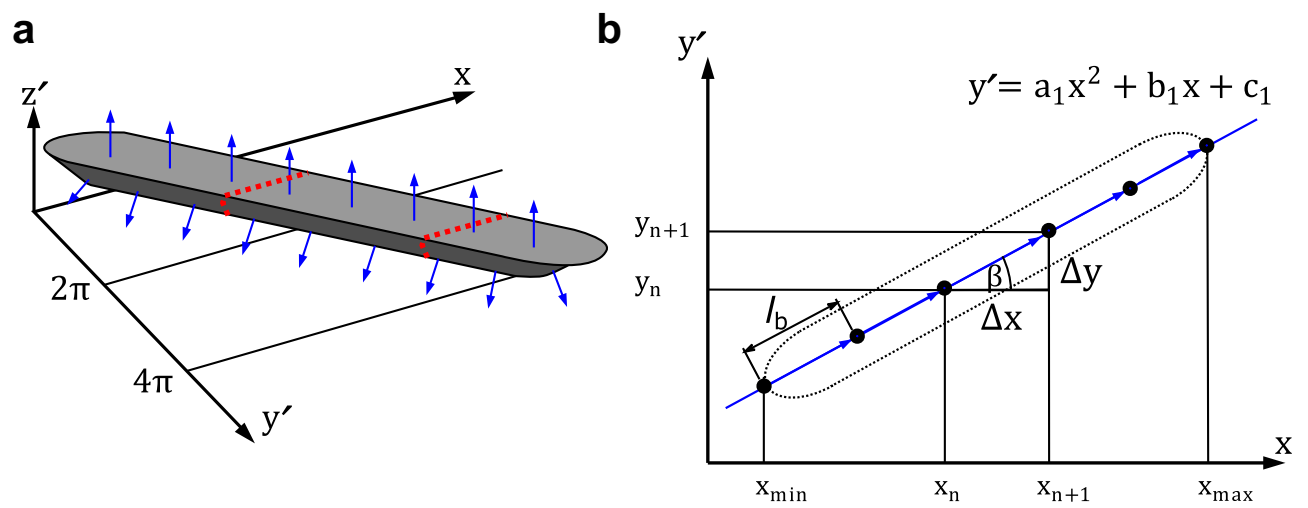

Publisher's note Springer Nature remains neutral with regard to jurisdictional claims in published maps and institutional affiliations.

The online version of the original article can be found at https://doi.org/ 10.1007/s00170-019-03540-5

Norbert Ackerl

ackerln@ethz.ch

Institute of Machine Tools and Manufacturing (IWF), ETH Zurich,

Leonhardstrasse 21, 8092 Zurich, Switzerland 